\title{
A study on the travel behavior of Shanghai International Students
}

\author{
Munalula Mundia ${ }^{1}$ \\ ${ }^{I}$ Glorious Sun School of Business and Management, Department of Tourism, Donghua University, Shanghai, \\ China
}

\begin{abstract}
With China's economy still remaining strong, more and more international students choose China as their study destination. While pursuing their studies, these students usually travel a lot in China as a way to also understand the Chinese culture. This paper investigates Shanghai international Students' travel behavior in China. The survey for the study was carried out at three Universities in Shanghai, Donghua University, East China Normal University and East China University of Science and Technology. The findings and recommendations for future studies are presented.
\end{abstract}

Keywords: China, Shanghai international students, tourism consumption, travel behavior.

\section{Introduction}

According to the Ministry of Education 2011 statistics, the number of international Students studying in China exceeded 290,000 for the first time. There were 292,611 international students from 194 countries and regions pursuing their studies in 660 higher institutions of education, research institutes and other education institutions in 31 provinces, autonomous regions and municipalities (Taiwan, Hongkong and Macao excluded).The number of international students studying in China increased by 27,521 , which is $10.38 \%$ more compared to 2010. The number of students under Chinese Government Scholarship Scheme reached 25,687, an increase by $14.73 \%$ from an earlier year. The number of self financed international students rose $9.98 \%$, which reached

266,924 .

As Shanghai being the economic center and more internationalized city in China, it attracts many foreign students to come and study in China. According to 2011 statistics, there were 47,731 international students from 180 countries and regions enrolled in 33 universities in Shanghai and 2 research institutes, a $10.9 \%$ increase from the previous year. The majority of students studying in Shanghai came from the top 5 countries, South Korea, Japan, France, Germany, and America.

As we can see from the statistics, the international student segment as a source of tourists has great potential as the population of international students is increasing every year. Therefore, it is important to research on this segment in order to understand the travel consumption behavior of international students as it shows great potential. Travel behavior research is very important for the tourism industry. According to saayman (2001:30), marketing research is essential in order to develop the right product or right package for the right market.

The outline of the paper is as follows: part 1 presents the research methodology, part 2 analyses the international students' travel consumption behavior, and finally part 3 gives the summary and recommendations for future studies.

\subsection{Research methodology}

\subsubsection{Target population to be studied}

The target population for this study was Korean, American and Tanzanian students currently studying in Shanghai. The questionnaires were administered at three different universities namely, Donghua University, East China Normal University and East China University of Science and Technology. I chose three Universities because I couldn't find enough students from each particular country at only one university. The survey was conducted on campus. The questionnaires were made available to the respondents in English and Mandarin. The questionnaires were handed to the students during break time and collected when the class session was over.

\subsubsection{The data collection and Analysis}

The data required for this study is divided into two parts, namely Secondary and primary data. The secondary data relevant to this study was obtained from published books, academic articles, and other sources such as theses and dissertations. For the primary data, quantitative method of research was used. A structured questionnaire was used to collect the data. A total of 270 questionnaires were given out and about 250 of them were considered valid for the study. The questionnaire has two parts. The first part asks about the basic information. The respondents should provide information such as their gender, nationality, age, education background, travel fund resources and other necessary information. The second part is on tourism consumption preferences. For example: tourist attractions, recreational places, transportation, food, shopping etc. The data 
analysis was done using Microsoft Excel and SPSS statistical package. Descriptive statistics was mainly used to do the analysis.

\subsection{Respondents' demographics}

The demographic characteristics of the students are shown in the table below.

Table 1: Demographic characteristics of respondents

\begin{tabular}{|c|c|}
\hline Characteristics & Percentage $(\%)$ \\
\hline \multicolumn{2}{|l|}{ Gender } \\
\hline Male & $40 \%$ \\
\hline Female & $60 \%$ \\
\hline \multicolumn{2}{|l|}{ Age in years } \\
\hline Under 18 & $3 \%$ \\
\hline $18-24$ & $58 \%$ \\
\hline $25-30$ & $19 \%$ \\
\hline $31-35$ & $11 \%$ \\
\hline $35-40$ & $4 \%$ \\
\hline Over 40 & $5 \%$ \\
\hline \multicolumn{2}{|l|}{ Nationality } \\
\hline Korea & $46 \%$ \\
\hline USA & $32 \%$ \\
\hline Tanzania & $22 \%$ \\
\hline \multicolumn{2}{|l|}{ Religion } \\
\hline Buddhist & $14 \%$ \\
\hline Christian & $56 \%$ \\
\hline Muslim & $8 \%$ \\
\hline Other & $22 \%$ \\
\hline \multicolumn{2}{|l|}{ Study period } \\
\hline Less than 1 month & $8 \%$ \\
\hline 1-3 months & $13 \%$ \\
\hline 4-5 months & $18 \%$ \\
\hline More than 6 months & $61 \%$ \\
\hline \multicolumn{2}{|l|}{ Study program } \\
\hline Chinese language & $62 \%$ \\
\hline Bachelor's degree & $18 \%$ \\
\hline Master's degree & $15 \%$ \\
\hline Doctor's degree & $5 \%$ \\
\hline \multicolumn{2}{|l|}{ Chinese level } \\
\hline Don't know & $4 \%$ \\
\hline Survival level & $24 \%$ \\
\hline Basic level & $52 \%$ \\
\hline Fluent & $20 \%$ \\
\hline \multicolumn{2}{|l|}{ Average travel expense } \\
\hline Under 1000RMB & $17 \%$ \\
\hline 1000-2000 RMB & $34 \%$ \\
\hline 2000-3000 RMB & $31 \%$ \\
\hline 3000-4000 RMB & $10 \%$ \\
\hline 4000-5000 RMB & $7 \%$ \\
\hline 5000-7000 RMB & $1 \%$ \\
\hline \multicolumn{2}{|l|}{ Sources of financial support } \\
\hline Parents/family & $56 \%$ \\
\hline Scholarship & $19 \%$ \\
\hline Salary from part time job & $18 \%$ \\
\hline Other & $7 \%$ \\
\hline
\end{tabular}

\section{Shanghai international students' travel consumption behavior analysis}

While travelling, five kinds of consumption occur. They are food, accommodation, transportation, tour and shopping. This part provides an analysis of the international students' travel consumption behavior. 


\subsection{Food preferences when travelling}

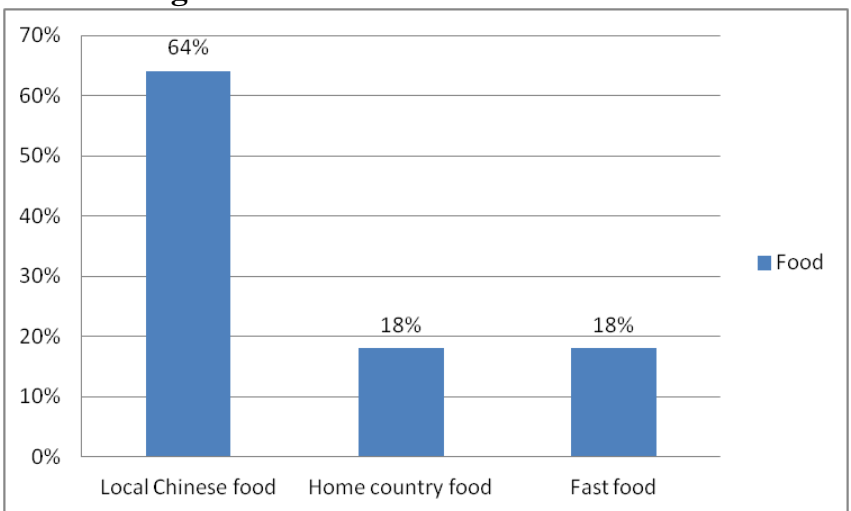

Figure 1 Food preferences when travelling

It is evident from figure 1 that most international students preferred to eat local Chinese food (64\%) when traveling. Home country food and fast food indicated $18 \%$ each. This is because international students like to try out the local cuisine, experience the food culture in China. Another reason is that local Chinese food is much cheaper compared to fast food and home country food in China. This finding contradicts with previous research that international students prefer to eat at fast food restaurants (Field, 1999:377-379; Shoham et al., 2004:4).

\subsection{Type of transportation preferred}

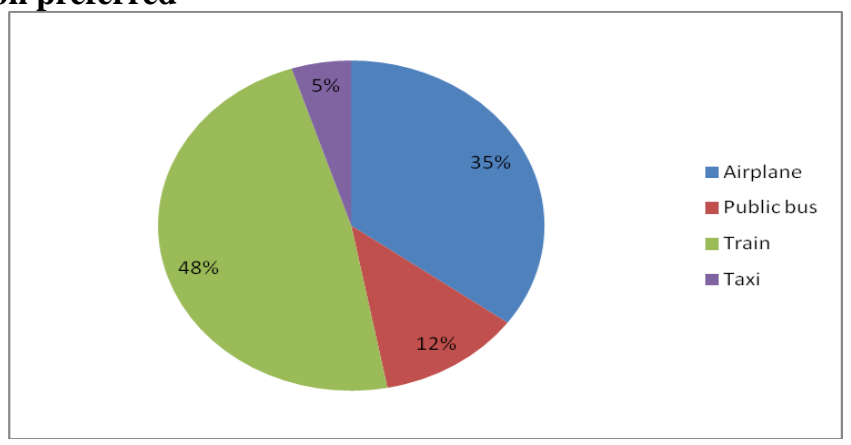

Chart 1 Type of transportation preferred

Chart 1 indicates that almost half of all the students prefer to travel by train $(48 \%)$, followed by airplane (35\%), public bus $(12 \%)$ and taxi $(5 \%)$. This because China's railway system is well developed and most cities can be easily travelled to by train. However, some international students still face difficulties with using the train because they do not know much about the Chinese railway system. Also it's very hard to travel by train in China during the holidays as the travel peak time occurs at the same time. It's usually very crowded and difficult to buy train tickets. So in this case some international students will choose to travel by airplane. Traveling by plane though is still not a popular mode of transportation in China and it can be slightly expensive for students. However, some students still choose to travel by plane because its faster and more comfortable. The other modes of transportation depend on the travel distance. Previous research also indicated that train and airplane were popular.

\subsection{Type of accommodation preferred}

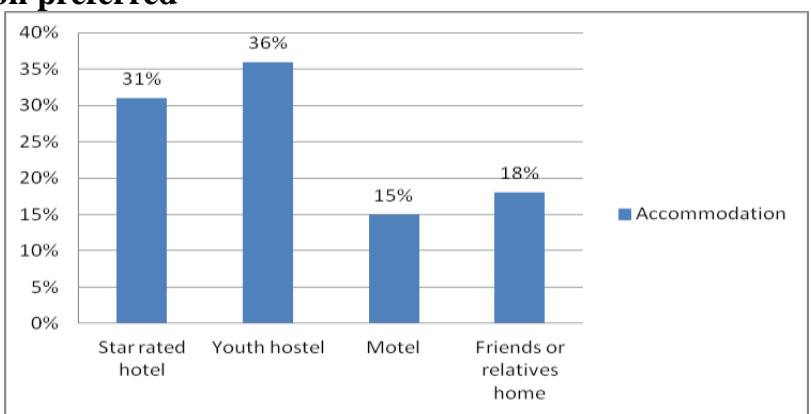

Figure 2 Type of accommodation preferred 
We can see from figure 2 that the majority of students (36\%) prefer to stay at youth hostels when traveling. This can be explained by the fact that in some other countries youth hostels have been there for a long time, well developed and popular among young people. Staying at a hotel (31\%), staying with relatives (18\%), and at a motel (15\%).Previous research supports this by indicating that international students prefer to stay at hotels, youth hostels and with friends (Field, 1999:377-379); Chadee \& Cutler, 1996:78; Haung, 2006: 6667;Pearce \& Son, 2004:343-347; Liu, 2008:219).

\subsection{Tour}

This part will include international students' preferences on travel companions, type of travel, travel motivations and tourist attractions.

\subsubsection{Travel companion}

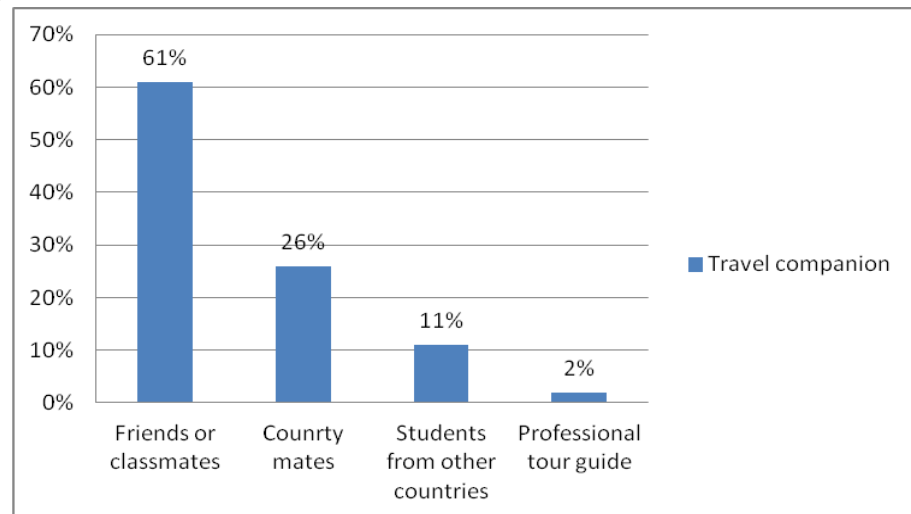

Figure 3 Travel companion

We can see from the figure 3 above that most international students prefer to travel with friends or classmates $(61 \%)$, followed by country mates accounting for $26 \%$. About $11 \%$ of international students choose to travel with students from other countries. Only $2 \%$ indicated that they would travel with a professional tour guide.

\subsubsection{Type of travel}

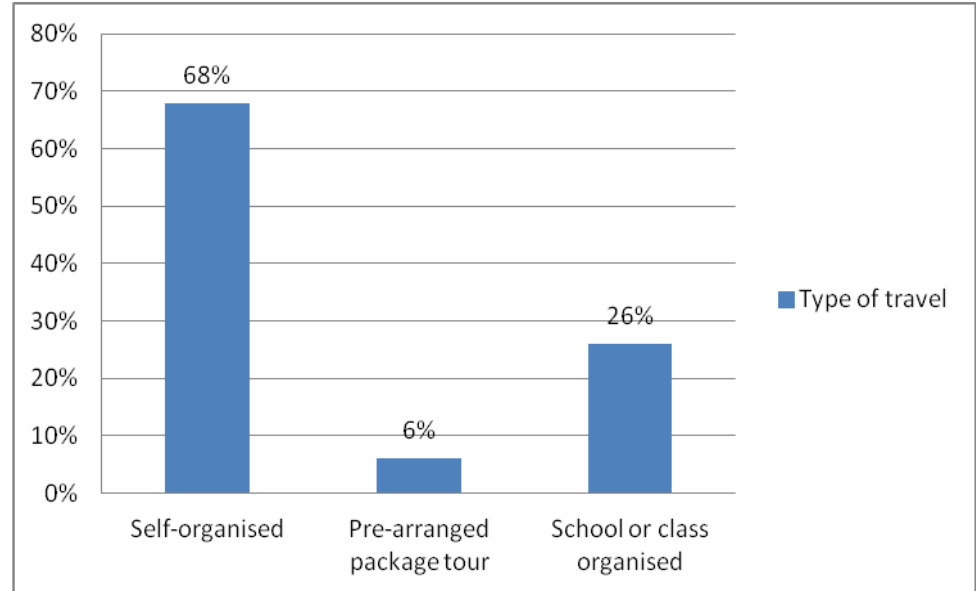

Figure 4 Type of travel

According to figure 4 international students prefer to organize their own travel (68\%). Twenty-six percent $(26 \%)$ chose school or class organized tour, while only $(6 \%)$ indicated pre-packaged tour by travel agents. This will depend on the length of the holiday the students plan to take, previous research found that students will make use of travel agents when planning longer holidays and organize shorter holidays by themselves. 


\subsubsection{Travel motivations}

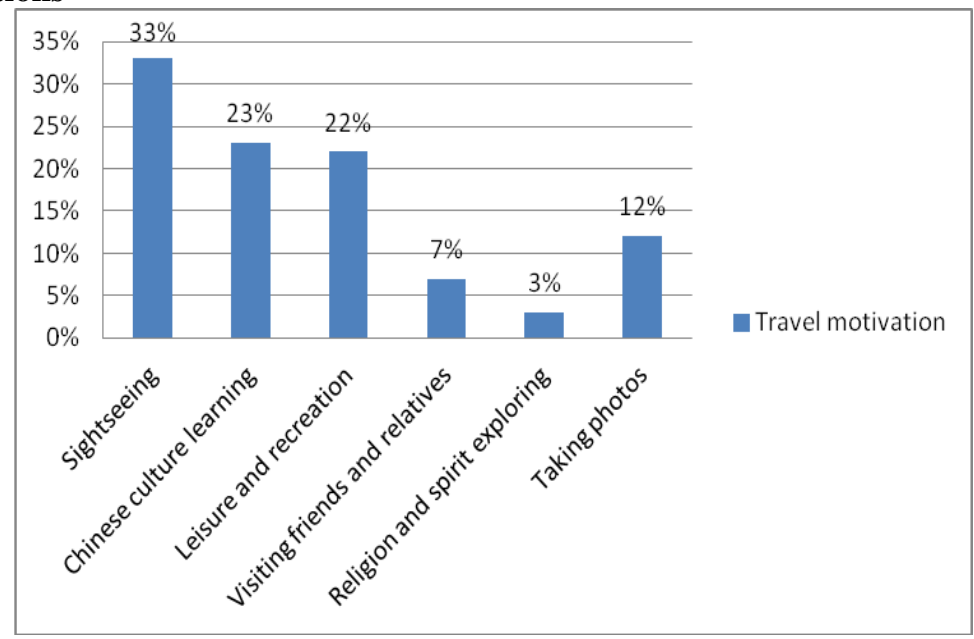

Figure 5 Travel motivations

Figure 5 clearly indicates that the main travel motivation for international students in Shanghai is sightseeing(33\%), followed by Chinese culture learning(23\%), leisure and recreation(22\%), taking photos (12\%), visiting friends and relatives(7\%). Only $3 \%$ choose religion and spirit exploring.

According to Neal et al. (2002:133) motives are the forces that initiate and direct travel behavior. A motive is a lasting disposition, an internal drive or push factor that causes the tourist to search for signs and events that contain the promise of reducing the prevalent drive (Gnoth, 1997:291). Different motivations or reasons to travel influence tourists differently. When looking at students, experiencing nature and partaking in nature based activities motivate backpacking students whereas socializing and spending time with friends, experiencing the city life motivate the general international students (Pearce \&Son 2004:349).Looking at general tourism populations, it is clear that motives differ among the tourists when going to different destinations, for example tourists visiting nature areas and parks are motivated mostly by exploration and partaking in nature based activities(Saayman and Van der Merwe, 2007) whereas tourists visiting events and festivals, resemble mostly socializing and novelty as well as experiencing different cultures as main motives (Backman et al., 1995; Schneider \& Backman, 1996; Park et al., 2008).

\subsubsection{Tourist attractions}

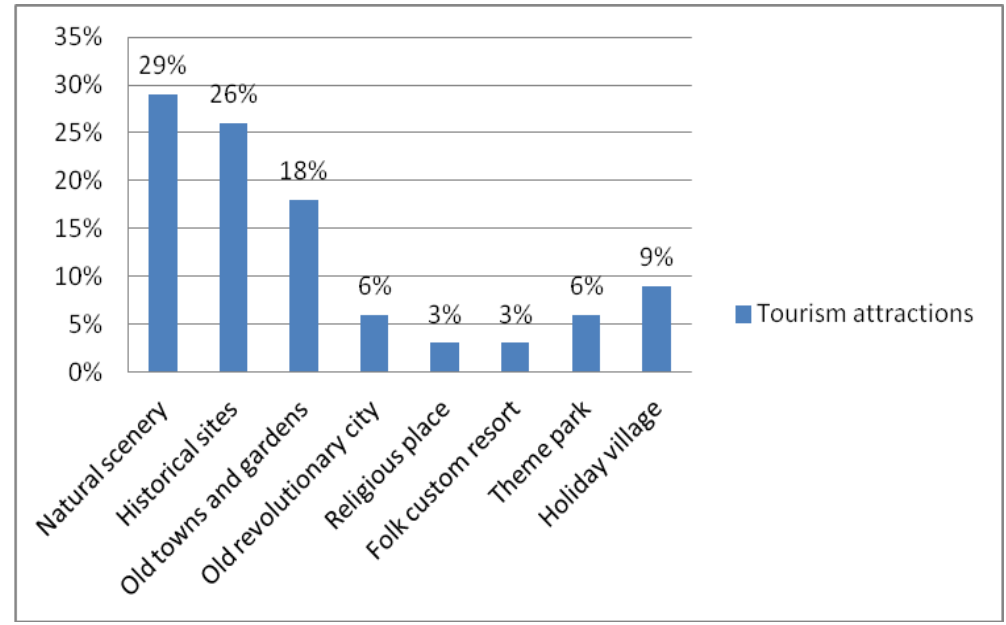

Figure 6 Tourist attractions

It is evident from figure 6 that the top three tourists' attractions for the international students are natural scenery (29\%), historical sites (26\%) and old towns and gardens (18\%). Holiday village (9\%), old revolutionary city and theme parks are both indicated $6 \%$. Only $3 \%$ of the international students indicated that they liked to travel to religious places and folk custom resorts, respectively. 


\subsection{Shopping}

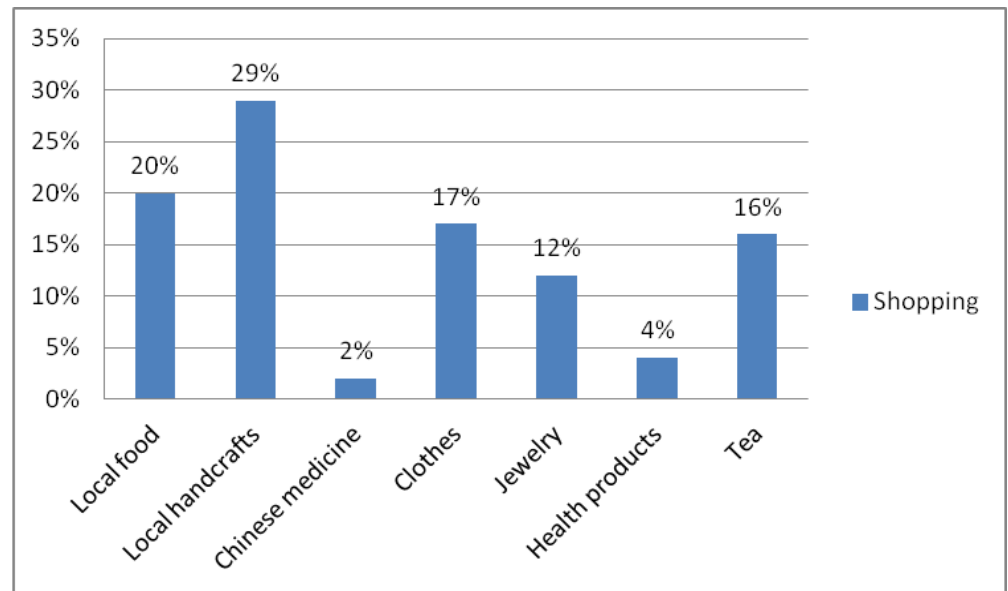

Figure 7 Shopping

It is evident in figure 7 that international students like to buy local handcrafts (29\%) as souvenirs when on holiday. This is followed by local food with $20 \%$. Clothes and tea are represented by $17 \%$ and $16 \%$ respectively. Twelve percent $(12 \%)$ chose jewelry. It is obvious that health products and Chinese medicine are the least popular products among international students with $4 \%$ and $2 \%$ respectively.

\subsection{Preferred Leisure and Recreational places}

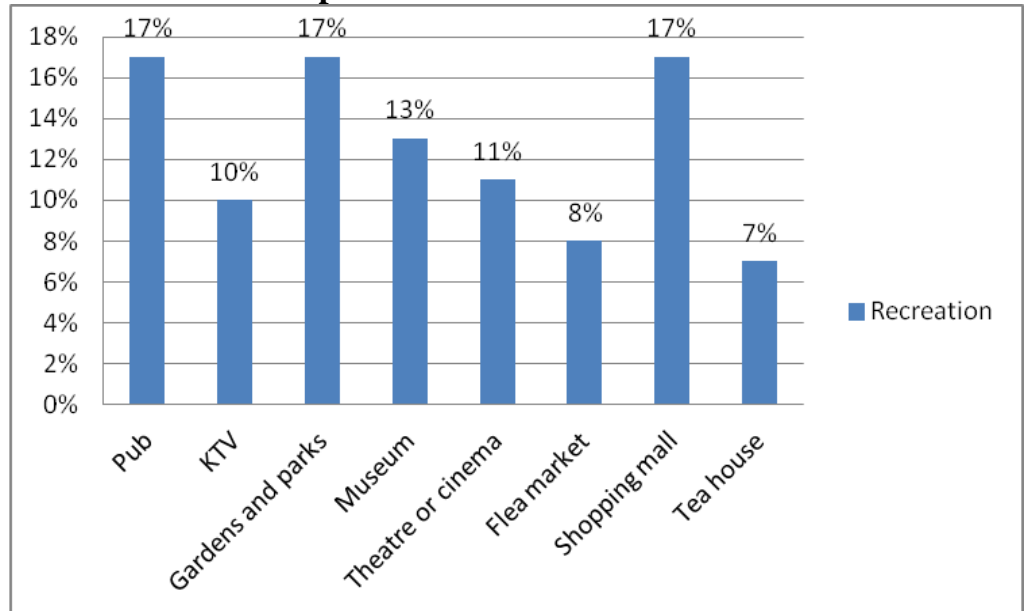

Figure 8 Preferred Leisure and Recreational places

Figure 8 indicates that the common recreational places for international students are the pub, gardens and park, and shopping mall, all with $17 \%$ each. Second we have museums (13\%), followed by theatre and KTV with $11 \%$ and $10 \%$ respectively. The least places of interest for recreation are flea market $(8 \%)$ and tea house $(7 \%)$.

\subsection{Summary}

\section{Summary and recommendations for future research}

While travelling, five kinds of consumption will occur. They are food, accommodation, transportation, tour and shopping. Most International students in Shanghai prefer to eat local food when travelling. Young people want to try new things and this is also a good way to experience Chinese culture. With regard to accommodation, Youth hostels are more popular. This is because they are cheap and convenient. Meanwhile some international students also prefer staying at star rated hotels. When it comes to transportation, the train and plane are the most popular. They prefer their travel mates to be friends or classmates, country mates and students from other countries. Their travel motivations are mainly sightseeing, Chinese culture learning and leisure and recreation. The most appealing tourist attractions for international students are natural scenery, historic sites and Chinese old towns and gardens. During travel, they prefer to buy local crafts and food as souvenirs. 


\subsection{Recommendations for future research}

- Similar studies should be done in the near future in order to compare results. Further research will not only lead to a greater understanding of students' travel behavior, but it will also reveal any future changes in tendencies.

- Comparative studies should be done on African students and students from Western and Eastern countries to find out more about any differences that might exist in their travel behavior. There is so much literature comparing the travel behavior of tourists from Western and Eastern countries but not on tourists from Africa.

- More research should also be done to find out any differences that might be there between male and female students when they travel.

\section{References}

[1] FIELD, A.M. 1999. The college student market segment: a comparative study of travel behavior of international and domestic students at a South Eastern University. Journal of travel research, 37:375-381.

[2] SHOHAM, A., SCHRAGE, C. \& VAN EEDEN, S. 2004. Student travel behavior: a cross-national study. Journal of travel and tourism marketing, 17(4):1-10.

[3] CHADEE, D.C. \& CUTLER, J. 1996. Insights into international travel by students. Journal of travel research, 35(2):75-80.

[4] LIU, G. 2008. Travel behavior and expenditure patterns of the Chinese university student and the associated Visiting Friends and Relatives (VFRs) markets in New Zealand. Waikato: University of Waikato. (Thesis - DPhil.) $500 \mathrm{p}$.

[5] HAUNG, R. 2006. A study of gender differences - the travel behavior of Chinese international students studying in the UK. Tourism, 54(1):63-69.

[6] PEARCE. P.L. \& SON, A. 2004. Youth tourism markets in Australia: comparing travel behaviors of international English language students and backpackers. Tourism, 52(4):341-350.

[7] SAAYMAN, M. 2001. Tourism marketing in South Africa. $2^{\text {nd }}$ ed. Potchefstroom: Leisure C Publications. 389 p.

[8] China Ministry of Education Statistics, 2011. Foreign students in China

[9] NEAL, C., QUESTER, P. \& HAWKINS, D. 2002. Consumer behaviour: implications for marketing strategy. $3^{\text {rd }}$ ed. Sydney: Irwin. $581 \mathrm{p}$.

[10] GNOTH, J. 1997. Tourists' motivation and expectation formation. Annals of tourism research, 24(2):283-304

[11] SAAYMAN, M. \& VAN DER MERWE, P. 2007. Travel motivations of tourists visiting Kruger National Park. (First International Tourism Conference of ICNT, 23-24 November. National Parks and Tourism. Heide: Germany.

[12] BACKMAN, K.F., BACKMAN, S.J., UYSAL, M. \& SUNSHINE, K.M. 1995. Event tourism: an examination of motivations and activities. Festival management and event tourism, 3(1):15-24.

[13] SCHNEIDER, I.E. \& BACKMAN, S.J. 1996. Cross-culturalequivalence of festival motivations: a study in Jordan. Festival managementand event tourism, 4(3/4):139-144.

[14] PARK, K., REISINGER, Y. \& KANG, H. 2008. Visitor motivation for attending South Beach wine and food festival, Miami Beach, Florida. Journal of travel and tourism marketing, 25(2):161-181. 